\title{
Energy efficient technology of obtaining heat- insulating material based on vermiculite
}

\author{
Zhumabuke Ospanova ${ }^{1}$, Nurgul Alibekova ${ }^{1, *}$ and Nursultan Satan ${ }^{2}$ \\ ${ }^{1}$ L.N.Gumilyov Eurasian National University, 010000, Astana, Kazakhstan \\ ${ }^{2}$ Karaganda State Technical University, 100012, Karaganda, Kazakhstan
}

\begin{abstract}
The paper presents energy-efficient technology with using microwaves to swell vermiculite. Replacement of traditional firing of vermiculite during exfoliation due to the use of microwave heating is promising, primarily due to lower energy costs.
\end{abstract}

\section{Introduction}

The implementation of energy-efficient policies is the main branch of industry and housing and communal services. The use of energy-saving technologies ensures the country's energy and environmental security, and the introduction of new innovative technologies stimulates the active interaction between the development of science and production.

In modern construction, the need for environmentally friendly, highly effective insulation materials has grown. These issues include expanded vermiculite, which have special properties: high degree of fire resistance, low average density and thermal conductivity, ecological compatibility.

Expanded vermiculite is widely used in construction as flame retardant coatings. Under fire conditions, the material does not emit any gases, which is an important advantage over other known fire-resistant and heat-insulating materials.

The practice of using vermiculite in construction as a non-combustible bulk insulation, fire retardant paints and vermiculite concrete shows the effectiveness of its application.

Products and materials used in construction are mainly made of expanded vermiculite. Expanded vermiculite is a highly porous material that is characterized by low density, low mechanical strength, biostability, non-toxic, non-flammable and durable.

Vermiculite is a mineral from the group of hydromica, having a layered structure, a product of secondary change (hydrolysis and subsequent weathering) of dark mica biotite and phlogopite.

The main property of vermiculite, which determines its application in construction, is the ability to increase in volume (swelling) 6-8 times when heated above $300^{\circ} \mathrm{C}$.

After extraction, vermiculite is crushed, and then in special furnaces with a high pipe in the flame of the gas burner it is burned to a temperature of $1000^{\circ} \mathrm{C}[2]$.

Flakes of vermiculite contain microparticles of water, as a result of which, with this heating, the water evaporates and hot steam enclosed in a dense space of scales breaks

\footnotetext{
* Corresponding author: nt_alibekova@mail.ru
} 
outward, expanding the vermiculite itself, and therefore after vesiculation, a large number of minute voids remain in the vermiculite, which ensures heat and sound insulation of the material.

An important factor in the wide use of vermiculite in construction is the availability of significant reserves of this raw material in Kazakhstan. In Western Kazakhstan, in the Aktyubinsk region there is a large deposit of vermiculite Karatas and Altyntskoye occupying the third place on the Eurasian subcontinent. In North Kazakhstan, in the Kostanay region there is the Barchinskoye deposit, in Central Kazakhstan, in the Karaganda region, deposit Neozhidannoye.

Since 2008, the development of the Kulantau deposit, located in the Tyulkubas region of the South Kazakhstan region for use, has begun, including as a bulk insulation in construction.

As a basis for the study, vermiculite from the Kulantaus deposit [3] was used in this study.

\section{Research energy-efficient technology with using microwaves to swell vermiculite}

The method of carrying out the research was to determine the heating mode, power and processing time in the microwave oven.

For the study, a common household microwave oven was used, intended for the quick preparation or heating of food. The microwave oven allowed to work in modes from 100 to 800 WT. Warm-up time in the ranges from several seconds to several minutes. Unlike a classical oven, in a microwave oven, the heating does not occur from the surface, but inside the material, since the radio waves penetrate deep enough throughout the volume.

At the first stage of the work, microwaves were treated separately with vermiculite and astringents.

As binder for the preparation of polymervermiculite products, epoxy and polyester resins with hardener were used. The experiments used epoxy resin ED-20 and polyester resin products of LLC Plastpoliefir (RF). SPEF-PV-0 - Polyester resin is unsaturated, filled, pre-accelerated, flame retardant, with low styrene emission, medium viscosity, with excellent impregnating capacity. The resin is characterized by rapid polymerization at a relatively long gel time.

Epoxy resin belongs to the group of non-heat-resistant, polyester resins and relates to heat-resistant materials.

The vermiculite swelling process was based on the technology of vermiculite sand swelling, confirmed by the patent of AS \#. 34345503, (19) KZ (13) A (11) 16294 (51) CO; In the 14/20 certificate №10 from 2005 [4].

The swelling of the vermiculite fraction up was performed to $2 \mathrm{~mm}$ in a microwave oven the 700 WT mode for 1-3 minutes, and the volume increase was 10-12 times (Fig. 1). When microwaves are processed in modes below $400 \mathrm{WT}$, vermiculite is not swollen.

The treatment with microwaves of epoxy and polyester resins is possible only in the 300-400 WT mode for 1-2 minutes with an increase in volume approximately by 2-3 times and forming inside the mass of large air pores. To obtain a heat insulating material in a microwave oven based on vermiculite, one-time cups for hot drinks, coated with heatresistant paraffin, were used as molds for pouring samples, which provides us with good insulation from bonding (Fig. 2). The cups were used for the experiment only once, although in some cases the sample was easily removed from the mold. 


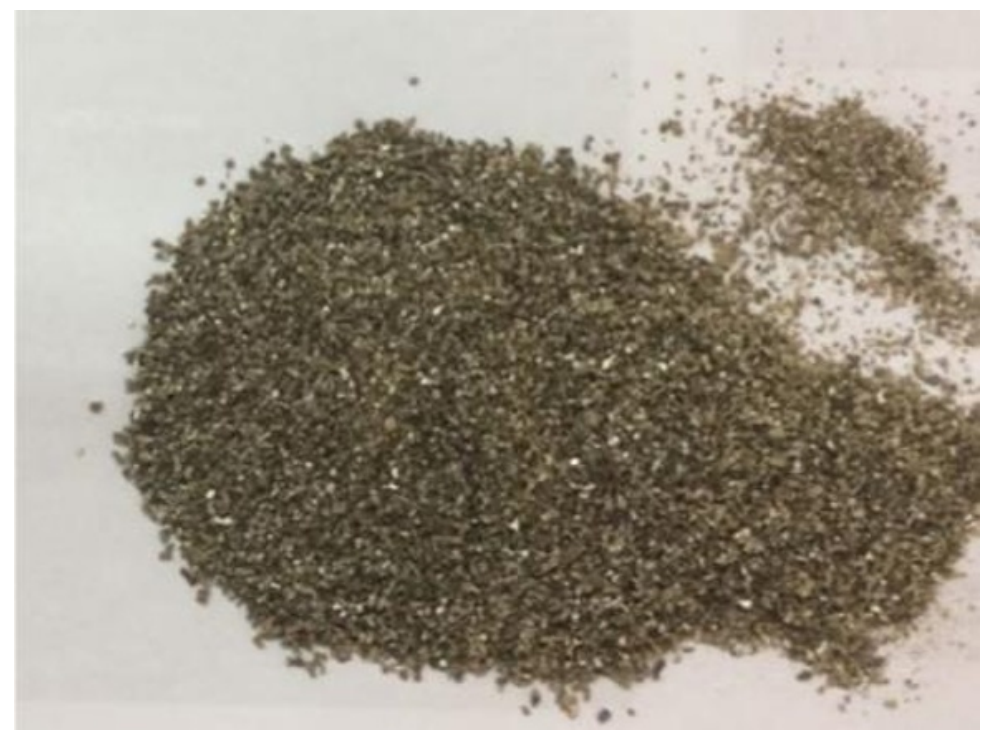

Fig. 1. Vermiculite swelled in the microwave

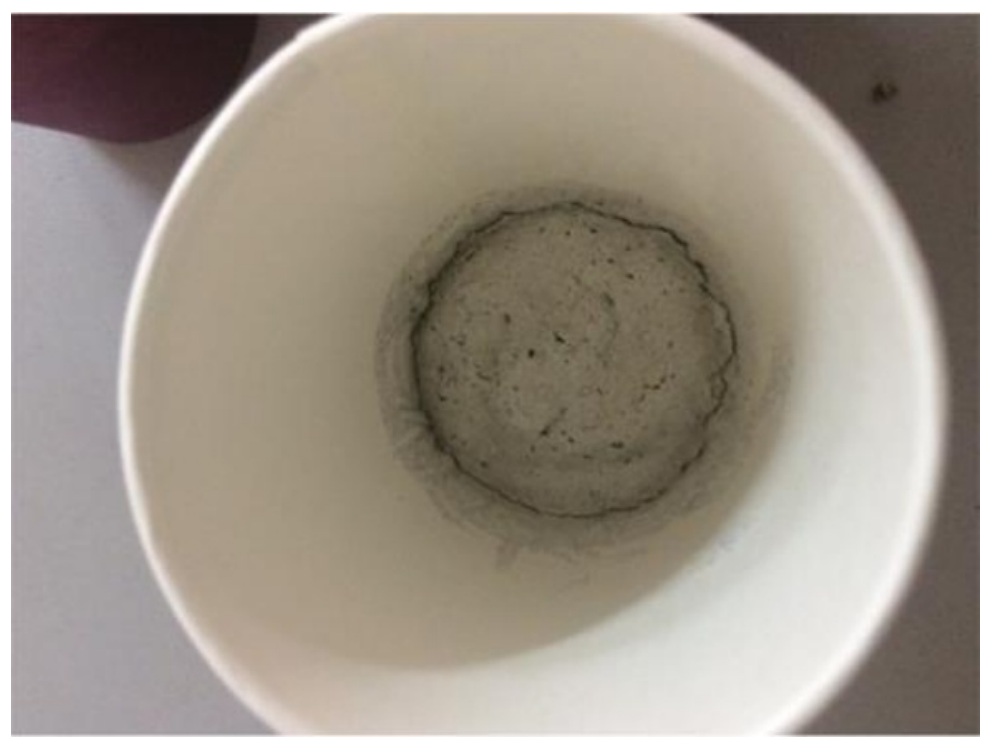

Fig. 2. Receiving heat insulation material in a single use cup

The formation of large pores in the bulk of the resin can be explained by a sharp increase in temperature when processed by microwaves. At a higher mode, occurs resin destruction - charring.

From these experiments, it was concluded that the simultaneous swelling in the microwave oven of a mixture of polymer and vermiculite is not possible, since under low conditions there is not sufficient swelling, and at high charring of the resin.

Therefore, the process of obtaining polymereromyculitis was divided into two stages. On the first, after grinding and fractionation, the vermiculite was swelled in a microwave oven in the mode of more than $700 \mathrm{~W}$, then thoroughly mixed with the resin and then reheated in a microwave oven, but already in the 400-450 WT mode.

For the experiment, different compositions were used in a weight ratio: 
- Resin with hardener + vermiculite: $1: 1 ; 1: 1.5$ and 1: 2 .

At a weight ratio of 1: 1, a material with sufficient high strength properties was obtained, but with an uneven structure, significant pores that were unevenly distributed throughout the volume. The increase in the content of vermiculite by one and a half times made the resulting material more homogeneous (Fig. 3) with smaller pores.

The most uniform material over the entire area was obtained by mixing the components at a ratio of 1: 2. The fine pores are evenly distributed throughout the volume of the material.

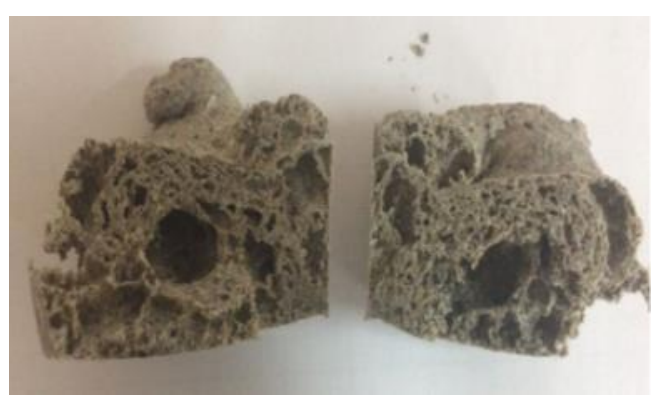

(a)

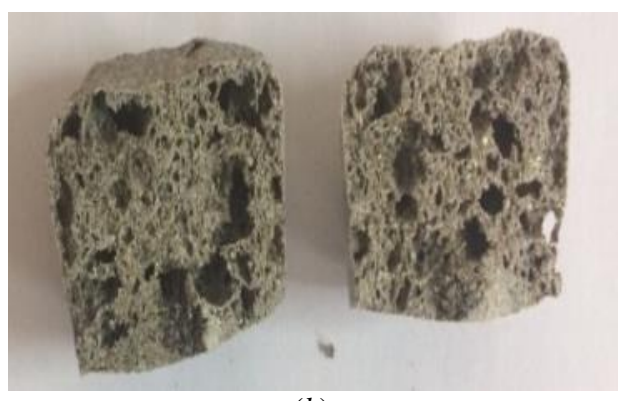

(b)

Fig. 3. Samples of polymervermiculite at a ratio of vermiculite: resin 1:1 (a) and 1: 1.5 (b)

Based on the performed experimental studies, the optimum weight ratio of vermiculite to resin to hardener is 1: 2 . The resulting heat-insulating material is the most homogeneous in structure and, accordingly, will have equal heat and sound insulation and strength properties (Fig. 4).

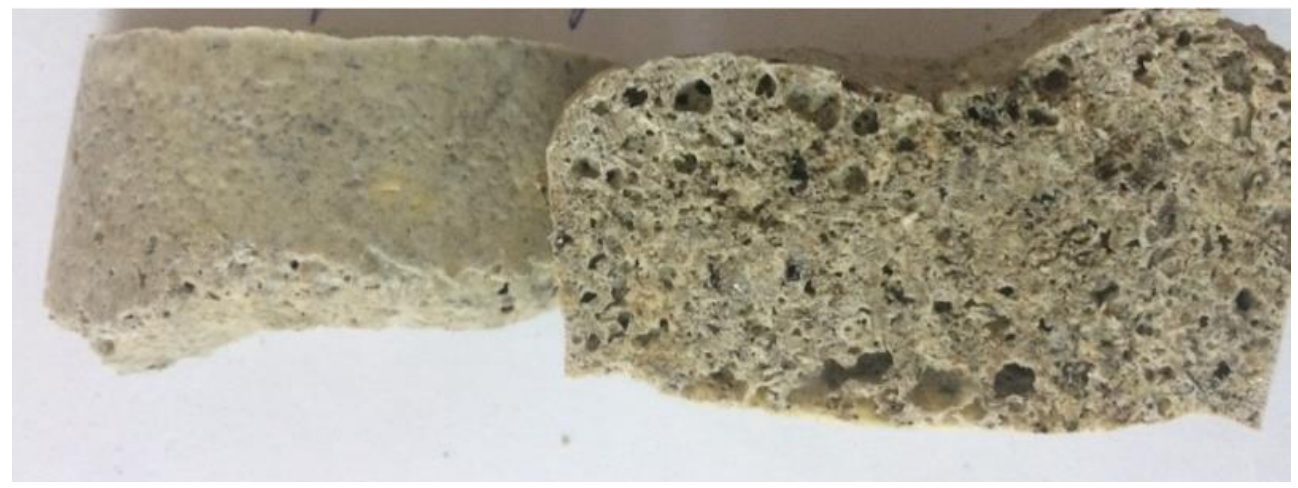

Fig. 4. Polymervermiculite at a weight ratio of 1:2

The obtained polymervermiculite can be used as a thermal insulation of buildings and structures.

\section{Conclusion}

Based on the research done, the following conclusions can be drawn:

1. Based on expanded vermiculite, thermal insulation materials with high strength and heat-sound-insulating properties can be obtained.

2. To obtain material based on vermiculite, energy-efficient technology using microwaves can be used. 


\section{References}

1. Message of the President of the Republic of Kazakhstan N.Nazarbayev to the people of Kazakhstan. (December 14b 2012).

2. Akhtyamov Ya. A., Bobrov B.S, Gemmerling G.V, Epelbaum M.B. Burning vermiculite, 128 (1972).

3. Baibatsha A.B. Geology of Mineral Deposits: Textbook, 368 (2008).

4. Ospanova Zh.N., Ospanov E.S, Orlova M.E. Author's certificate No. 34345503, (19) KZ (13) A (11) 16294 (51) CO; (In the 14/20 bul. №10 of 2005) 